\title{
Abstracts
}

\section{Medicine in Society}

John Wattis

Susan Lowrey and Roger Briggs, Boom in private rest homes in Southampton: impact on the elderly in residential care, British Medical fournal, 296, ( 1988 ), $54^{\mathrm{I}-543 .}$

L. Gregory Pawlson, Hospital length of stay of frail elderly patients: primary care by general internists versus geriatricians, Fournal of the American Geriatrics Society, 36, ( 1988 ), 202-208.

I developed a distinct 'Alice in Wonderland' feeling as I read these two articles. The first is a brief and interesting study by Susan Lowrey, a medical student, and Roger Briggs, a senior lecturer in geriatric medicine. Since changes in regulations in 1983 allowed elderly people in Britain to claim supplementary benefit payments to help meet the cost of care in private rest homes, there has been a boom in such provision, nowhere more marked than on the south coast of England. Before the boom, most local authority social services operated assessment procedures to ration the small amount of Part III residential accommodation provided by local government. There has been no such rationing of private care, the sole condition being that applicants for supplementary benefit must meet criteria of financial need.

Various objections have been raised. Lack of assessment might lead to care for those who do not need it. Large amounts of money go in a relatively unsupervised way into private residential care whilst government policies of 'community care' are not implemented because of the lack of finance. Meanwhile, it has been assumed that local authority homes will continue to care for people of increasing dependency. Lowrey and Briggs's paper examines levels of disability in $5^{1}$ private and seven local authority rest homes in 1986 and considers comparable $198 \mathrm{I}$ data from four of the local authority homes. They used the Clifton Assessment Procedure for the Elderly (CAPE) to study over $45^{\circ}$ residents in the private sector and over 200 in the public sector.

The populations had similar mean ages (around 83 years) in 1986 and there were more women in the private $(84 \%)$ compared with the public $(73 \%)$ homes. The distribution of CAPE dependency grades was almost identical in both types. It is however worth noting that 32 
( $16 \%$ ) of the local authority and $68(15 \%)$ of the private residents scored CAPE grade A, indicating apparent independence. Among local authority home residents, whereas in 198239 per cent of residents had been in the least demanding care categories of $A$ and $B$ and 39 per cent in the most demanding categories of $\mathrm{D}$ and $\mathrm{E}$, by 1986 these percentages had changed to 52 and 28 respectively.

There are many implications of this study. The greater proportion of women in private care, probably due to the smaller average size of private homes, may produce less flexible accommodation with more need for segregation of the sexes. The similar dependency levels suggest that the private sector is not admitting large numbers of less dependent residents and that self selection operates to keep their levels of disability close to those of local authority homes. The 15 per cent of people in CAPE grade A does not necessarily indicate misplacement; factors not measured by CAPE may produce losses of independence.

The temporal trend indicates that when the pool of residential care is expanded, the general level of disability goes down. The authors augue that this is because people who could manage at home with better community care are being admitted. Government policies to promote community care are not being implemented, but public money has been poured into private residential care. Another explanation, not offered by the authors, is that the relatively 'free' market in Southampton has allowed residential care (public and private) to find its 'proper' level. This interpretation would be unpopular on the political right since it would not remove the argument that more money needs to be spent on community care and that it should not come from reducing the availability of residential care. Another point, which the authors do not make, is that the phenomena they have observed could be an example of the north-south divide of Great Britain. Private care has not expanded so rapidly in the north and the south is at an apparent advantage. Whether this will be institutionalised by the implementation of the Griffiths reforms remains to be seen.

If this paper causes unease about the way that public policy is being implemented in Britain, the other, from the United States, is more disquieting. In the USA, Medicare prospective payments are now based on 'diagnosis-related groups' (DRGs). Under the new Medicare system, some patients generate more revenue than cost (revenue winners), others generate more cost than revenue (revenue losers). Given that the length of hospital stay tends to increase with age and the number of diagnoses, frail elderly people are likely to be revenue losers. 
Dr Pawlson decided to compare the length of stay (as proxy for cost) of a group of patients admitted by geriatricians with a control group of admissions by general internists (equivalent to British consultants in general medicine). Pawlson uses 'primary care' to describe the activities of the general internists and geriatricians, whereas British usage refers to the activities of family doctors.

Pawlson found that, despite access to similar rehabilitation personnel and facilities, the 15.8 days mean length of stay for a matched general internal medicine group was significantly longer $(P<0.05)$ than the 8.8 days for the geriatric medicine group. When broken down by place of both origin and discharge, it was apparent that the general internists dealt with fewer nursing home origin and discharge cases. The geriatric physicians had shorter lengths of stay in the nursing home/nursing home, home/home and particularly the home/nursing home care groups, this last group staying 2.I times longer than predicted in geriatric care and 3.3 times longer in general internist care. The author comments that the use of DRG groups does not adjust for case-mix severity, but he was unable to find any evidence that the general internists were dealing with more severe or complex cases. Nor was there any difference in the proportion or pattern of re-admissions, though this could have been because of the greater proportion of the geriatric group discharged to nursing home care (62 as against $36 \%$ ).

The most worrying point is that "patients in this study admitted by either physician group would be viewed by hospitals as having a long length of stay and therefore as potential revenue losers under DRG reimbursement'. Dr Pawlson also concludes that physicians caring for a disproportionate number of patients requiring post-hospital nursinghome care would be likely to be viewed unfavourably as potential revenue losers. He concludes that 'the use of a clinical management approach similar to that used by our geriatric team might allow frail elderly patients to be dealt with with minimal financial risk to the hospital' (my italics).

One admires a country where the health care information enables the kind of analysis performed by Dr Pawlson. On the other hand, from our British position of relatively low health spending, one asks whether all this costly information gathering is worthwhile if it could result in hospitals discouraging the admission of frail elderly patients. Even with highly efficient care, they are likely to be revenue losers. Another useful lesson is the contribution of the waiting time for nursing-home care of this impasse. I suspect that most of us in Britain would be thrilled if the 
average length of stay of patients going from home to residential/ nursing-home care was only 20-30 days. Perhaps the Griffiths Report will alter that too.

St James's University Hospital, Leeds

\section{Religion and Ageing}

\section{Mannes Tidmarsh}

Arthur H. Becker, Pastoral theological implications of the ageing process. Religion and Ageing, 2, 3 (1986), 13-30.

Becker begins by remarking on a tendency for some Christian ministers caring for old people to take on the task of counsellor or social worker, thereby avoiding offering 'true pastoral care', by which he means giving attention to 'the spiritual/theological issues involved in the ageing process'. He also identifies a subtle ageism to which some pastors are prone, which leads them to assume that the spiritual/ theological problems of those aged over 65 years are all alike.

The author goes on to argue that pastoral care will be improved if it is realised that the three epochs of ageing give rise to distinct spiritual/theological concerns : for the younger elderly 'What shall I do with my life?'; for the middle-old, 'What about my dying?'; and for the old-old, 'Why must I suffer so?'. He then briefly relates these issues to Jung's polarities and Erikson's 'crisis work' in later life. Becker attributes the life direction/purpose dilemmas of the younger elderly to the entry into retirement, which is interpreted not only as formal retirement from work but also as the enforced withdrawal from responsible social roles, not least roles within the church community. $\mathrm{He}$ cites several studies in support of his contention that concern about death is at its highest among the middle-old group (aged 71-75 years). He emphasises the importance at this stage of life of the virtue of hope, arising both from reflection on the pattern of events in one's past life and from God's promise of a 'new creation'.

The focus of concern for the frail elderly, whom Becker seems to equate with the old-old, is personal pain and a sense of abandonment. He quotes at length Sölles's description of three phases of suffering: mute suffering, anguished outcry of lament, and liberation and change. Pain tends initially to isolate the sufferer and may lead old people in particular to withdraw from supportive relationships in order to avoid becoming a burden. The pastor's role is to reach out and help 